\title{
PENERAPAN ALGORITMA AES (ADVANCED ENCRYPTION STANDARD) DALAM PENYANDIAN KOMPRESI DATA
}

Erfan Wahyudi ${ }^{1}$, Bahtiar Imran ${ }^{2}$, Subektiningsih ${ }^{3}$, Akhmad Muzakka ${ }^{4}$

STMIK Mataram ${ }^{1,2}$

Universitas Amikom Yogyakarta ${ }^{3}$

Universitas Islam Indonesia ${ }^{4}$

erfan.wahyudie@gmail.com

\begin{abstract}
Abstrak - Dengan perkembangan teknologi komputer saat ini, pertukaran informasi dari suatu pihak ke pihak lain sangatlah diperlukan. Informasi yang dikirimkan tersebut biasanya tidak ingin diketahui oleh pihak yang tidak berkepentingan terutama pihak-pihak yang tidak bertanggungjawab. Ancaman keamanan terhadap informasi tersebut dapat berupa interupsi, intersepsi, modifikasi, dan fabrikasi. Ancaman-ancaman ini dapat memanipulasi hingga menghapus data yang ditransmisikan melalui komputer. Untuk mengatasi ancaman tersebut, diperlukanlah suatu cara agar informasi tersebut tidak dapat diketahui oleh pihak lain. Salah satu caranya dalah dengan menggunakan kriptografi. Dalam paper ini algoritma kriptografi yang digunakan adalah AES (Advanced Encryption Standard) yang dibuat oleh Rijmen dan Daemen dari Belgia. Hasilnya, Algoritma AES atau Rijndael merupakan algoritma simetri yang sangat cocok digunakan untuk berbagai keperluan yang berkaitan dengan kriptografi saat ini termasuk penyandian, salah satunya adalah untuk penyandian sandi-lewat untuk file kompresi.
\end{abstract}

\section{Kata kunci: AES (Advanced Encryption Standard), Algoritma Rijndael, Kriptografi, Kompresi Data}

\section{LATAR BELAKANG}

Dengan perkembangan teknologi komputer yang semakin pesat, banyak dimanfaatkan sebagai media untuk pertukaran informasi dari suatu pihak ke pihak lain. Informasi-informasi yang ditransmisikan tersebut biasanya tidak ingin dilihat oleh orang lain yang tidak berkepentingan dan tidak bertanggung jawab agar tidak disalah gunakan. Beberapa ancaman yang biasanya ditemukan dalam pertukaran informasi berupa interupsi, intersepsi, modifikasi, dan fabrikasi (Munir, 2006).

Model ancaman interupsi ini dapat mengganggu ketersediaan data, misalnya data yang ada dapat dihapus sehingga pihak yang membutuhkan atau penerima yang seharusnya dituju tidak dapat menemukan data tersebut. Ancaman intersepsi merupakan ancaman terhadap kerahasiaan data seperti penyadapan informasi yang ditransmisikan dan digunakan oleh yang tidak berhak sehingga merugikan pemilik yang sah.

Ancaman modifikasi mengakibatkan kesalahan dalam penerimaan informasi sehingga informasi yang diterima tidak sesuai dengan keinginan penerima maupun pengirimnya. Sedangkan ancaman fabrikasi merupakan ancaman terhadap integritas data karena informasi yang berhasil dicuri oleh pihak yang tidak bertanggungjawab kemudian dipalsukan dan dikirimkan kepada penerima seolaholah berasal dari pengirim yang sah (Dony, 2006).

Untuk mengantisipasi ancaman-ancaman tersebut, diperlukanlah suatu cara agar informasi tersebut tidak dapat diketahui oleh pihak lain. Salah satu caranya adalah dengan menggunakan kriptografi.

Kriptografi sudah dikenal sejak ribuan tahun yang lalu dan terus menerus dikembangkan hingga saat ini. Beberapa pengembangan telah dilakukan oleh berbagai pihak dari berbagai negara di bagian barat. Karena banyaknya jumlah yang dikembangkan, maka dibuatlah seuhan standar algoritma sehingga dapat dipergunakan dalam berbagai aplikasi. NIST (National Institute of Standard and Technology) mempublikasikan suatu algoritma pengenkripsian data baru untuk menggantikan algoritma DES (Data Encryption Standard) yang memiliki beberapa kelemahan. Algoritma bari ini dinamakan AES (Advanced Encryption Standard) atau Rijndael. Meskipun masih baru, algoritma ini sudah digunakan di berbagai aplikasi, salah satunya adalah untuk penyandian password. Penggunaan algoritma ini sudah sering kita lihat pada perangkat lunak untuk melakukan kompresi data.

Dalam penelitian ini membahas penerapan algoritma AES untuk melakukan penyandian data yang dikompres.

\section{LANDASAN TEORI}

a. Kriptografi

Kriptografi merupakan suatu ilmu yang mempelajari bagaimana cara menjaga kerahasiaan suatu data agar tetap aman saat dikirmkan dari si pengirim ke penerima tanpa mengalami gangguan dari pihak-pihak yan tidak 
berhak dan bertanggung jawab untuk mengetahui pesan yang dikirimkan tersebut.

Ada empat tujuan mendasar dari ilmu kriptografi ii yang juga merupakan aspek keamanan informasi, yaitu:

1) Kerahasiaan, merupakan layanan yang digunakan untuk menjaga isi dari informasi kecuali yang memiliki otoritas atau kunci rahasia untuk membuka informasi yang telah disandi.

2) Integritas Data, berhubungan dengan penjagaan dari perubahan data secara tidak sah. Untuk menjaga integritas suatu data, sebuah sistem harus memiliki kemampuan untuk mendeteksi manipulasi data oleh pihakpihak yang tidak berhak, antara lain penyisipan, penghapusan, pensubstitusian data lain kedalam data yang sebenarnya.

3) Autentikasi, berhubungan dengan identifikasi atau pengenalan, baik secara kesatuan sistem maupun informasi itu sendiri. Dua pihak yang saling berkomunikasi harus saling memperkenalkan diri. Informasi yang dikirimkan melalui kanal harus diautentikasi keaslian, isi data, waktu pengiriman data dan lainnya.

4) Non Repudiasi, merupakan suatu usaha untuk mencegah terjadinya penyangkalan terhadap pengiriman atau terciptanya suatu informasi oleh yang mengirimkan atau membuat data tersebut.

Dalam kriptografi juga dikenal beberapa istilah yang biasa digunakan sebagai berikut:

1) Plaintext (M), merupakan pesan yang akan dikirimkan dan berisi data asli yang belum dienkripsi.

2) Chipertext (C), merupakan pesan ter-enkripsi atau yang sudah tersandi yang merupakan hasil dari enkripsi.

3) Enkripsi (Fungsi E), adalah proses pengubahan plaintext menjadi chipertext.

4) Dekripsi (Fungsi D), merupakan kebalikan dari enkripsi yakni mengubah chipertext menjadi plaintext, sehingga berubah menjadi data awal atau data aslinya.

5) Kunci, merupakan suatu bilangan yang dirahasiakan yang digunakan dalam proses enkripsi dan dekripsi.

Kriptografi itu sendiri terdiri dari dua proses utama yakni proses enkripsi dan proses dekripsi. Seperti yang telah dijelaskan diatas, proses enkripsi mengubah plaintext menjadi chipertext (dengan menggunakan kunci tertentu yang sudah disepakati) sehingga isi informasi pada pesan tersebut sukar dimengerti seperti pada gambar 1 dibawah.

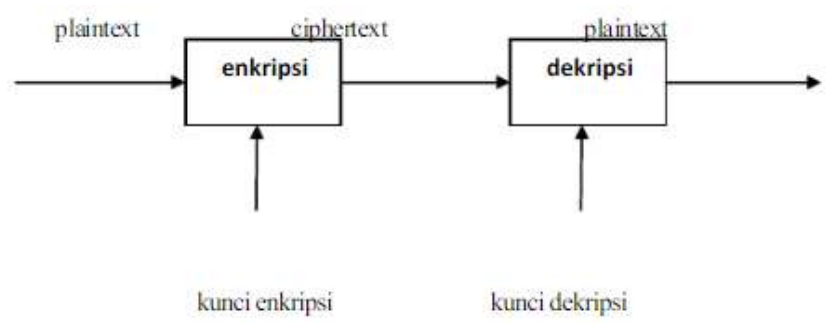

Gambar 1. Diagram Proses Enkripsi dan Dekripsi

Peranan kunci sangatlah penting dalam proses enkripsi dan dekripsi (disamping pula algoritma yang digunakan) sehingga kerahasiaannya sangatlah penting, apabila kerahasiaanya terbongkar, maka isi dari pesan dapat diketahui oleh yang tidak memiliki otoritas.

Secara matematis, prosses enkripsi merupakan pengoperasian fungsi $E$ (enkripsi) menggunakan e (kunci enkripsi) pada $M$ (palintext) sehingga dihasilkan C (chipertext), notasinya:

$$
E_{e}(M)-C
$$

Sedangkan untuk proses dekripsi, merupakan pengoperasian fungsi $D$ (dekripsi) menggunakan $d$ (kunci dekripsi) pada C (chipertext) sehingga dihasilkan M (plaintext), notasinya:

$$
D_{d}(C)=M
$$

Sehingga dari dua hubungan diatas berlaku:

$$
D_{d}\left(E_{e}(M)\right)=M
$$

\section{b. Algoritma Kriptografi}

Berdasarkan kunci yang dipakai, algoritma kriptografi dibagi menjadi tiga macam:

1) Hash Function

Fungsi hash sering disebut sebagai fungsi satu arah (one-way function). Fungsi ini mengubah suatu input menjadi output, tetapi output tersebt tidak dapat dikembalikan mejadi bentuk semula. Salah satu manfaatnya adalah penggunaan sidik jari (fingerprint) yang digunakan sebagai identitas pengirim pesan. Fungsi lain adalah untuk kompresi dan message digest. Contoh algoritma fungsi ini adalah MD-5 dan SHA.

\section{2) Asimetri}

Pada algoritma ini, digunakan dua buah kunci yang berhubungan yang disebut dengan kunci umum dan kunci pribadi. Kunci umum dapat 
dipublikasikan sehingga pesan dapat dienkripsikan tetapi tidak dapat didekripsikan dengan kunci tersebut. Kunci pribadi hanya boleh digunakan oleh pihak yang berhak untuk mendekripsikan pesan yang terenkripsi tersebut. Algoritma yang menggunakan kunci publik dan pribadi ini antara lain Digital Sgnature Alogrithm (DSA), Rivest Shamir-Adleman (RSA), DiffieHellman ((DH) dan sebagainya.

\section{3) Simetri}

Algoritma ini menggunakan kunci yang sama untuk mengenkripsi dan mendekripsi data. Untuk mendekripsi data, penerima menggunakan kunci yang sama dengan kunci yang digunakan pengirim untuk mengenkripsi data. Contoh dari algoritma ini adalah Data Encryption Standard (DES), International Data Encryption Algorithm (IDEA), Advanced Encryption Standard (AES), dan sebagainya.

\section{ALGORITMA AES (ADVANCED ENCRYPTION STANDART) ATAU RIJNDAEL}

Saat proses enkripsi, dibutuhkan empat macam operasi yang dilakukan secara berulang-ulang dalam beberapa putaran dan menggunakan kunci chiper. Ada 3 macam jumlah putaran algoritma yang digunakan seperti pada tabel 1 berikut (AES Standard):

Tabel 1. Jumlah Putaran Pengoperasian AES.

\begin{tabular}{|c|c|c|c|}
\hline Tipe & $\begin{array}{c}\text { Panjang } \\
\text { Kunci }\end{array}$ & $\begin{array}{c}\text { Panjang } \\
\text { Blok Input }\end{array}$ & $\begin{array}{c}\text { Jumlah } \\
\text { Putaran }\end{array}$ \\
\hline AES-128 & 128 bit & 128 bit & 10 \\
\hline AES-192 & 192 bit & 128 bit & 12 \\
\hline AES-256 & 256 bit & 128 bit & 14 \\
\hline
\end{tabular}

\section{a. Operasi}

Ada empat macam operasi yang dilakukan pada setiap putaran:

1) Transformasi Subtitusi Byte

Dalam operasi ini, setiap byte yang akan dienkripsi disubstitusikan dengan nilai byte yang lain menggunakan S-box. S-box dibuat dari multiplicative inverse dari angka yang diberikan dalam Rijndael's finite field yang kemudian ditransformasikan dengan affine transformation [4]: $\left[\begin{array}{llllllll}1 & 0 & 0 & 0 & 1 & 1 & 1 & 1 \\ 1 & 1 & 0 & 0 & 0 & 1 & 1 & 1 \\ 1 & 1 & 1 & 0 & 0 & 0 & 1 & 1 \\ 1 & 1 & 1 & 1 & 0 & 0 & 0 & 1 \\ 1 & 1 & 1 & 1 & 1 & 0 & 0 & 0 \\ 0 & 1 & 1 & 1 & 1 & 1 & 0 & 0 \\ 0 & 0 & 1 & 1 & 1 & 1 & 1 & 0 \\ 0 & 0 & 0 & 1 & 1 & 1 & 1 & 1\end{array}\right]\left[\begin{array}{l}x_{0} \\ x_{1} \\ x_{2} \\ x_{3} \\ x_{4} \\ x_{5} \\ x_{6} \\ x_{7}\end{array}\right]+\left[\begin{array}{l}1 \\ 1 \\ 0 \\ 0 \\ 0 \\ 1 \\ 1 \\ 0\end{array}\right]$

Gambar 1: Affine Transformation

Hasilnya kemudian di-xor dengan $99_{10}$ atau $0 \times 63_{16}$ atau $1100011_{2}$. Operasi matriks dengan xor ini ekuivalen dengan persamaan:

$b_{i}^{\prime}=b_{i} \quad b_{(i+4) \bmod 8} \quad b_{(i+5) \bmod 8} \quad b_{(i+6) \bmod 8} \quad b_{(i+7) \bmod 8} \quad c_{i}$ dengan $b^{\prime}, b$, dan $c$ adalah array 8 bit dan nilai $c$ adalah 01100011 .

Proses tersebut menghasilkan masing-masing nilai dari elemen tabel $S$-box yang hasilnya sebagai berikut.

Tabel 2. S-Box

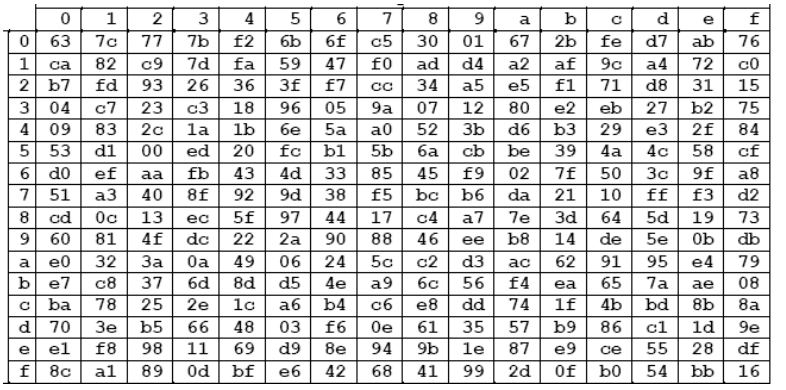

Seperti yang telah diketahui sebelumnya, AES merupakan algoritma simetri, yang berarti tabel subtitusi yang dibutuhkan untuk mengenkripsi berbeda dengan untuk mendekripsi. Untuk acuan tersebut, digunakanlah tabel $S$-box inversi sebagai seperti tabel 3 berikut.

Tabel 3. S-box Inversi

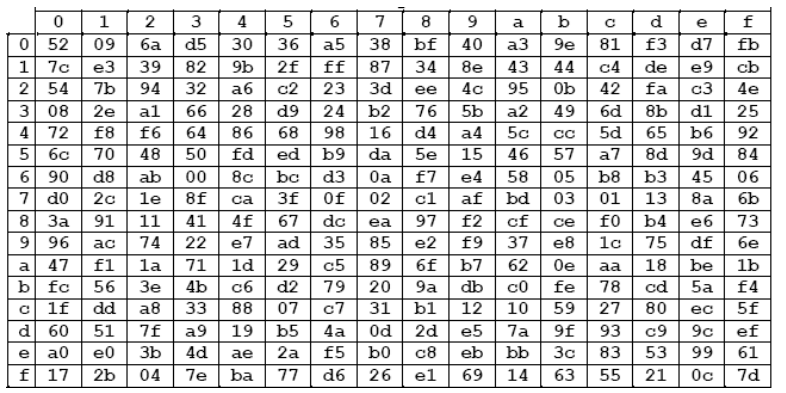

Sebagai contoh, input yang akan dienkripsikan adalah 95950819

$4 \mathrm{f} 6 \mathrm{~b} 5 \mathrm{c} 6 \mathrm{e} \mathrm{c} 8$

898026 fc 75

$4 \mathrm{e} 6 \mathrm{c}$

Dengan menggunakan $S$-box, hasil dari operasi ini adalah

2a 2 a 30 d4 
$847 f$ a $9 f$

e8 a7 cd f7

b0 9d $2 \mathrm{f} 50$

Jika hasil tersebut ingin dikembalikan ke nilai semula sebelum operasi, nilai-nilainya dapat disubtitusikan dengan menggunakan tabel S-box inversi. Operasi transformasi subtitusi byte pada proses enkripsi dan dekripsi tidak dilakukan pada putaran pertama. Operasi ini hanya dilakukan pada putaran kedua hingga terakhir.

\section{2) Transformasi Pergeseran Baris}

Pada operasi ini, byte-byte pada setiap baris digeser secara memutar dengan pergeseran yang berbeda dari tiap-tiap baris. Setiap baris digeser dengan aturan tertentu untuk jenis panjang blok yang berbeda. Baris pertama blok untuk semua jenis panjang blok (128, 196, dan 256 bit) tidak digeser. Baris kedua untuk semua jenis panjang blok digeser 1 ke kiri. Pergeseran baris ketiga dan keempat untuk panjang blok 128 dan 196 bit berbeda dengan 256 bit. Pada panjang blok 128 dan 196 bit, baris ketiga digeser ke kiri sebanyak dua kali dan baris keempat digeser ke kiri sebanyak tiga kali. Pada panjang blok 256 bit, baris ketiga digeser ke kiri sebanyak tiga kali dan baris keempat digeser ke kiri sebanyak empat kali. Untuk lebih jelasnya, proses tersebut dapat dilhat pada gambar 2 dan gambar 3 berikut.

\begin{tabular}{|l|l|l|l|}
\hline $\mathrm{S}_{0,0}$ & $\mathrm{~S}_{0,1}$ & $\mathrm{~S}_{0,2}$ & $\mathrm{~S}_{0,3}$ \\
\hline $\mathrm{S}_{1,0}$ & $\mathrm{~S}_{1,1}$ & $\mathrm{~S}_{1,2}$ & $\mathrm{~S}_{1,3}$ \\
\hline $\mathrm{S}_{2,0}$ & $\mathrm{~S}_{2,1}$ & $\mathrm{~S}_{2,2}$ & $\mathrm{~S}_{2,3}$ \\
\hline $\mathrm{S}_{3,0}$ & $\mathrm{~S}_{3,1}$ & $\mathrm{~S}_{3,2}$ & $\mathrm{~S}_{3,3}$ \\
\hline
\end{tabular}$\rightarrow$\begin{tabular}{|l|l|l|l|l|}
\hline $\mathrm{S}_{0,0}$ & $\mathrm{~S}_{0,1}$ & $\mathrm{~S}_{0,2}$ & $\mathrm{~S}_{0,3}$ \\
\hline $\mathrm{S}_{1,1}$ & $\mathrm{~S}_{1,2}$ & $\mathrm{~S}_{1,3}$ & $\mathrm{~S}_{1,0}$ \\
\hline $\mathrm{S}_{2,2}$ & $\mathrm{~S}_{2,3}$ & $\mathrm{~S}_{2,0}$ & $\mathrm{~S}_{2,1}$ \\
\hline $\mathrm{S}_{3,3}$ & $\mathrm{~S}_{3,0}$ & $\mathrm{~S}_{3,1}$ & $\mathrm{~S}_{3,2}$ \\
\hline
\end{tabular}

Gambar 2: Operasi pada Blok 128 bit

\begin{tabular}{|l|l|l|l|l|l|l|l|}
\hline $\mathrm{S}_{0,0}$ & $\mathrm{~S}_{0,1}$ & $\mathrm{~S}_{0,2}$ & $\mathrm{~S}_{0,3}$ & $\mathrm{~S}_{0,4}$ & $\mathrm{~S}_{0,5}$ & $\mathrm{~S}_{0,6}$ & $\mathrm{~S}_{0,7}$ \\
\hline $\mathrm{S}_{1,0}$ & $\mathrm{~S}_{1,1}$ & $\mathrm{~S}_{1,2}$ & $\mathrm{~S}_{1,3}$ & $\mathrm{~S}_{1,4}$ & $\mathrm{~S}_{1,5}$ & $\mathrm{~S}_{1,6}$ & $\mathrm{~S}_{1,7}$ \\
\hline $\mathrm{S}_{2,0}$ & $\mathrm{~S}_{2,1}$ & $\mathrm{~S}_{2,2}$ & $\mathrm{~S}_{2,3}$ & $\mathrm{~S}_{2,4}$ & $\mathrm{~S}_{2,5}$ & $\mathrm{~S}_{2,6}$ & $\mathrm{~S}_{2,7}$ \\
\hline $\mathrm{S}_{1,0}$ & $\mathrm{~S}_{3,1}$ & $\mathrm{~S}_{3,2}$ & $\mathrm{~S}_{3,3}$ & $\mathrm{~S}_{3,4}$ & $\mathrm{~S}_{1,5}$ & $\mathrm{~S}_{3,6}$ & $\mathrm{~S}_{3,7}$ \\
\hline \multicolumn{7}{|c}{$\mathrm{S}$} \\
\hline
\end{tabular}

\begin{tabular}{|l|l|l|l|l|l|l|l|}
\hline $\mathrm{S}_{0,0}$ & $\mathrm{~S}_{0,1}$ & $\mathrm{~S}_{0,2}$ & $\mathrm{~S}_{0,3}$ & $\mathrm{~S}_{0,4}$ & $\mathrm{~S}_{0,5}$ & $\mathrm{~S}_{0,6}$ & $\mathrm{~S}_{0,7}$ \\
\hline $\mathrm{S}_{1,1}$ & $\mathrm{~S}_{1,2}$ & $\mathrm{~S}_{1,3}$ & $\mathrm{~S}_{1,4}$ & $\mathrm{~S}_{1,5}$ & $\mathrm{~S}_{1,6}$ & $\mathrm{~S}_{1,7}$ & $\mathrm{~S}_{1,0}$ \\
\hline $\mathrm{S}_{2,3}$ & $\mathrm{~S}_{2,4}$ & $\mathrm{~S}_{2,5}$ & $\mathrm{~S}_{2,6}$ & $\mathrm{~S}_{2,7}$ & $\mathrm{~S}_{2,0}$ & $\mathrm{~S}_{2,1}$ & $\mathrm{~S}_{2,2}$ \\
\hline $\mathrm{S}_{3,4}$ & $\mathrm{~S}_{3,5}$ & $\mathrm{~S}_{3,6}$ & $\mathrm{~S}_{3,7}$ & $\mathrm{~S}_{3,0}$ & $\mathrm{~S}_{3,1}$ & $\mathrm{~S}_{3,2}$ & $\mathrm{~S}_{3,3}$ \\
\hline
\end{tabular}

Gambar 3: Operasi pada Blok 256 bit

Sebagai contoh, hasil operasi ini terhadap input yang nilainya adalah output dari hasil operasi subtitusi byte sebelumnya adalah sebagai berikut

2a 2 a $30 \mathrm{~d} 4$

$7 \mathrm{f} 4 \mathrm{a}$ 9f 84

cd $\mathrm{f} 7 \mathrm{e} 8 \mathrm{a} 7$

$50 \mathrm{~b} 09 \mathrm{~d} 2 \mathrm{f}$
3) Transformasi Percampuran Kolom

Transformasi ini mengoperasikan blok pada masing-masing kolomnya. Setiap kolom diperlakukan sebagai four-term polynomial dengan cara Galois Field (GF) (28) dan dimodulokan dengan $\mathrm{x}^{4}+1$ dengan polinom tetap $a(x)$ [3], yaitu: $a(x)=\{03\} x^{3}+\{01\} x^{2}+\{01\} x+\{02\}$

4) Transformasi Penambahan Kunci

Dalam operasi transformasi ini, digunakanlah upakunci untuk masing-masing putaran yang berasal dari kunci utama dengan menggunakan jadwal kunci Rijndael (Rijndael's key schedule) yang ukuran upakunci terebut sama dengan ukuran blok yang akan diproses. Upakunci tersebut kemudian di-xor dengan blok input sehingga diperoleh hasilnya [7].

Sebagai contoh, jika inputannya adalah:

c3 c5 0808

78 a 4 ff 36

00 ff 3636

$285 \mathrm{f} 0102$

Dan diperoleh upakunci

$368 \mathrm{a} \mathrm{c0} \mathrm{f} 4$

ed cf 76 a 6

08 a3 b6 78

$3131276 \mathrm{e}$

Maka hasilnya adalah

a6 34 1a 00

$24 \mathrm{dd} \mathrm{fl} 0 \mathrm{e}$

62 a $873 \mathrm{cf}$

48 b9 $5 \mathrm{~d} 61$

\section{b. Putaran}

Seperti yang telah diketahui sebelumnya pada Tabel 1, jumlah putaran pengoperasian blok input untuk setiap macam panjang blok berbeda-beda. Akan tetapi, jumlah putaran untuk proses enkripsi dan dekripsi tetap sama. Prossk enkripsi dan dekripsi dapat digambarkan seperti gambar 4 dan 5 berikut [2]. 


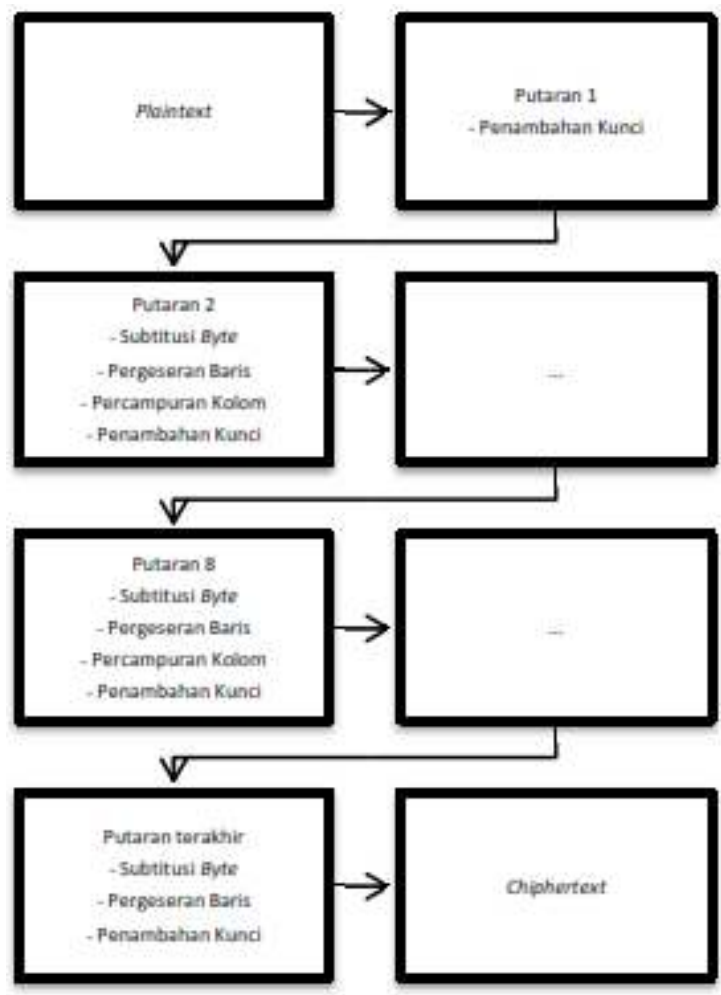

Gambar 4. Diagram Proses Enkripsi

Pada gambar 4, merupakan alur proses enkripsi yang dilakukan dengan empat putaran yang sudah dijelaskan sebelumnya. Sedangkan proses dekripsi digambarkan pada gambar 5 berikut:

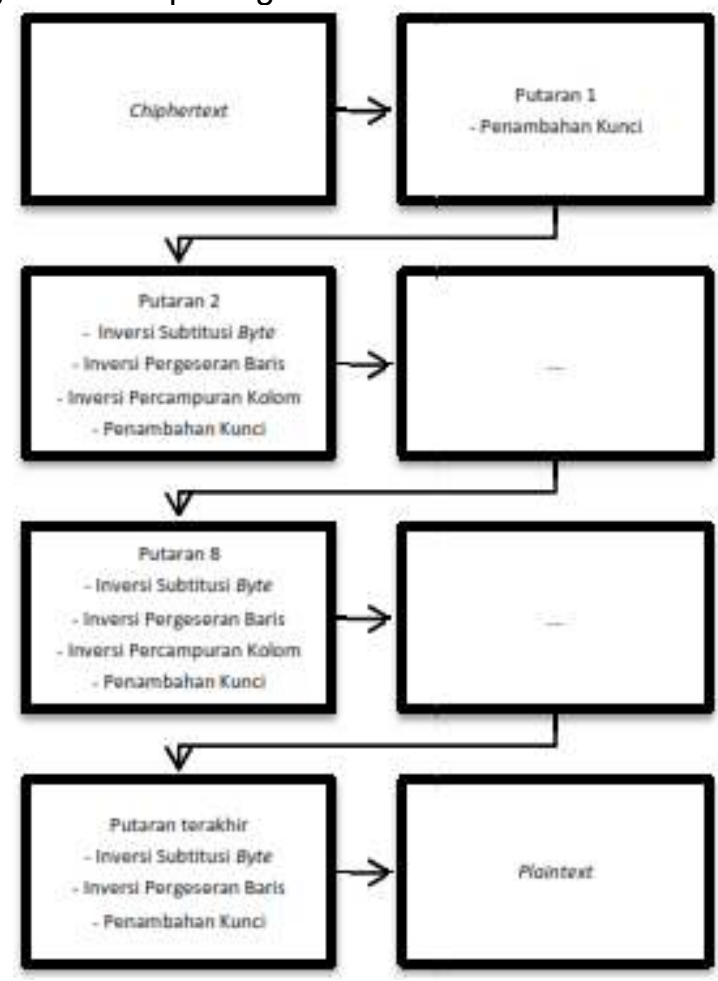

Gambar 5. Diagram Proses Dekripsi

\section{PENGGUNAAN AES DALAM ENKRIPSI DAN DEKRIPSI SANDI-LEWAT FILE ZIP}

Dalam pembuatan sandi-lewat pada file yang sudah terkompresi, algoritma penyandian bukan digunakan untuk kunci sandi-lewatnya saja tetapi untuk file tersebut. Pada menu ketika suatu folder atau file yang telah disiapkan akan dikompresi, ada pilihan untuk memberikan sandi-lewat atau tidak, yang tampak pada gambar 6 berikut dengan menggunakan 7zip.

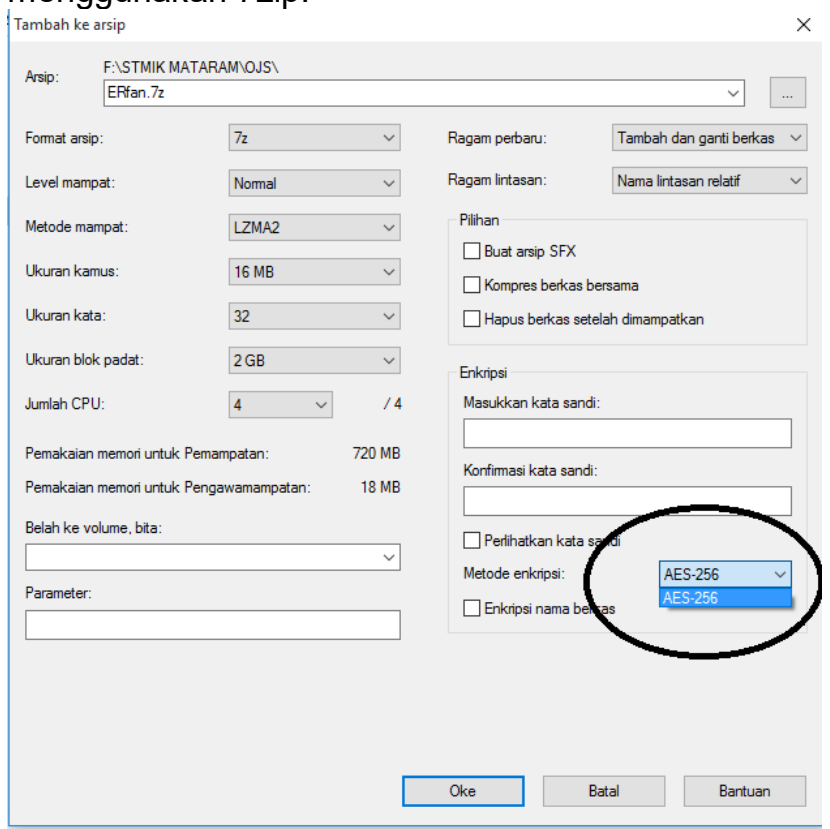

Gambar 6. Menu Pemilihan Penggunaan Sandi-lewat

Pada gambar 6 terdapat pilihan untuk mengenkripsi file dengan menggunakan sandi-lewat. Pada menu tersebut terdapat juga pemilihan metode enkripsi. Pada aplikasi 7-zip pada gambar tersebut, pemilihan metode enkripsi yang dapat digunakan adalah AES-256 [8]. Dalam proses enkripsi, file yan telah dikompresi dienkripsi dengan sandi-lewat. Tentu saja ukuran hasil enkripsi tidak berbeda jauh dengan hasil kompresi sebelum dienkripsi. Hasil enkripsi pada file zip bertambah sedikit karena dalam format file enkripsi terdapat empat macam isi, yaitu nilai salt, nilai verifikasi sandi lewat, kode autentikasi dan data yang dienkripsi [9].

\section{KESIMPULAN}

Algoritma AES (Advanced Encryption Standard) atau Rijndael merupakan algoritma simetri yang sangat cocok dipakai untuk berbagai keperluan yang berkaitan dengan kriptografi saat ini. Algoritma ini banyak dipakai untuk keperluan penyandian. Salah satunya adalah untuk penyandian sandi-lewat untuk file kompresi. Algoritma ini tentu saja sangat sesuai dengan 
berbagai aplikasi kompresi, yang pada pembahasan diatas menggunakan kompresi 7zip sehingga dapat digunakan di berbagai merk aplikasi kompresi.

\section{DAFTAR PUSTAKA}

Rinaldi Munir, Matematika Diskrit, Prodi Teknik Informatika ITB, 2006

Dony Ariyus, Kriptografi, Kemanana Data dan Komunikasi, Graha IImu, 2006

Spesification for the Advanced Encryption Standard (AES),

http://csrc.nist.gov/publication/fips/fips197/fips$\underline{197 . p d f}$

Rijndael S-Box, http://en.wikipedia.org/wiki/Rijndael S-box

The Advanced Encryption Standard (Rijndael), http://www.quadibloc.com/crypto/co040401.ht $\underline{\mathrm{m}}$

Rijndael,

http://csrc.nist.gov/archive/aes/rijndael/misc/ni ssc2.pdf

Advanced Encryption Standard, http://en.wikipedia.org/wiki/Advanced Encrypti on Standard

Guidance on Encryption of Email and Email Attachments, http://www.ucl.ac.uk/cert/EmailEncryption .html 